\title{
Optimization of culture conditions for high frequency in vitro shoot multiplication in sugarcane (Saccharum officinarum L.)
}

\author{
M. K. Sharma ${ }^{1 *}$, R. S. Sengar ${ }^{1}$, P. Chand ${ }^{2}$, R. Singh ${ }^{3}$, S. Gupta ${ }^{4}$, M. K. Yadav ${ }^{1}$ and A. Singh ${ }^{1}$ \\ ${ }^{1}$ Department of Agriculture Biotechnology, ${ }^{2}$ Department of Genetics \& Plant Breeding, ${ }^{3}$ Department of Plant \\ Pathology, ${ }^{4}$ Department of Molecular Biology and Genetic Engineering, Sardar Vallabhbhai Patel University of \\ Agriculture \& Technology, Meerut-250110 (U.P.), INDIA \\ *Corresponding author. E-mail : manojmeerut94@gmail.com
}

Received: November 29, 2015; Revised received: May 24, 2016; Accepted: August 14, 2016

\begin{abstract}
Present study deals with the optimization of various culture conditions for initiating high frequency in vitro shoot multiplication in two early maturing high yielding sugarcane genotypes namely Co98014 \& Co89003. On the behalf of the findings of this study, it was concluded that the temperature, photoperiod and culture media $\mathrm{pH}$ affected the frequency of in vitro shoot multiplication in both sugarcane genotypes at a significant level. In both genotypes high frequency shoot multiplication was recorded at growth room temperature $25^{\circ} \mathrm{C}, 16 \mathrm{~h} / 8 \mathrm{~h}$ light/dark photoperiod and culture media pH 6.0. Genotype Co89003 exhibited highest shoot regeneration and multiplication under various culture conditions. The present study suggests the necessity of investigation of these culture conditions separately upon individual sugarcane genotypes prior to develop efficient in vitro plant regeneration protocol for commercial purposes.
\end{abstract}

Key words: Culture environment, Shoots regeneration, Sugarcane, Tissue culture

\section{INTRODUCTION}

Sugarcane (Saccharum officinarum L.) is an important agro-industrial crop of both tropical and subtropical regions of the world that is grown at commercial scale in a wide range of climates from hot dry environment near sea level to cool and moist environment at higher elevations (Alam et al., 1995). It is the world's largest crop by production quantity (FAOSTAT, 2015). Sugarcane is commercially grown over an area of about 27.2 mha producing about 1877 million metric tons of sugarcane with an average productivity of 70.9 tons/ha (FAOSTAT, 2015). Brazil stands first in the world with respect to area (10.2 million hectares) and production (768.09 million tons) followed by India, China, Thailand and Pakistan respectively. India is the second largest producer of sugar (24.55 million tons) including traditional cane sugar sweeteners, khandsari $\&$ gur with sugarcane cropping area of about 5.06 million hectares and cane production of 352.14 million tons (FAOSTAT, 2015). Economically, sugarcane is an important industrial raw material for sugar and allied industries producing alcohol, acetic acid, butanol, paper, plywood, industrial enzymes, animal feeds, etc. (Arencibia et al., 1998). Being a member of family Poaceae, sub-family Panicoideae and tribe Andropogoneae, sugarcane is cultivated in about 127 countries with the contribution of approximately $75 \%$ of total sugar production in the world (Commodity Research Bureau, 2015). Sugar industry is the second largest industry in India after textiles and is an agro-based industry plays a vital role in the socio-economic transformation of the country (FAO, 2013).

Sugarcane is conventionally propagated through vegetative means by using seed in the form of setts where, the low multiplication rate and accumulation of sett borne diseases and pests are the major challenges. Development of tissue culture technologies, especially micropropagation using shoot tips for rapid and high multiplication of disease-free planting material at commercial scale has been an important step towards quality seed production in sugarcane (Hendre et al., 1975; Jalaja et al., 2008). The success of an efficient and reliable micropropagation protocol is critically affected by various environmental and nutritional factors including the role of plant growth regulators, temperature, $\mathrm{pH}$, photoperiod, light intensity, humidity, gaseous environment etc, so their optimization is necessary for achieving desirable goals (Ramanand and Lal, 2004; Jo et al., 2008; Mishra, 2011; Sharma et al., 2015). In this regard, a little work has been done in case of sugarcane (Ramanand and Lal, 2004; Singh, 2005; Mishra, 2011; Sengar et al., 2011; Sharma et al., 2015). It is well known that the optimal environmental conditions for plant growth and development often vary between species and sometimes genotypes (Mishra, 2011). So, it is necessary to investigate the effects of above mentioned environmental conditions separately upon individual genotypes prior to developing efficient in vitro plant regeneration protocols for 
commercial purposes. Therefore, the present study was conducted for optimization of various culture conditions for initiating high frequency in vitro shoot multiplication from shoot tip explants in two early maturing high yielding sugarcane genotypes namely Co89003 \& Co98014.

\section{MATERIALS AND METHODS}

In vitro establishment of cultures: Very young and healthy tops (ca. 10-12 cm) of sugarcane genotypes i.e. Co89003 \& Co98014 excised from 4-6 months old field grown plants, maintained under the natural conditions in rain out shelter at Agricultural Biotechnology Research Station, S.V.P. University of Agriculture \& Technology, Meerut, Uttar Pradesh, were used as explants to initiate the cultures. All the open green leaves were removed and about 5-6 cm long spindle segments were dissected and washed thoroughly under running tap water for 30 min containing 2-3 drops of Tween-20 (Hi-Media, India). Thereafter, the explants were surface sterilized with $0.1 \%(\mathrm{w} / \mathrm{v})$ aqueous mercuric chloride $\left(\mathrm{HgCl}_{2}\right)$ solution for $5 \mathrm{~min}$ followed by the treatments for one minute with fungicide [Carbendazim, $0.1 \%(\mathrm{w} / \mathrm{v})$ ] and bactericide [Streptomycin, $0.1 \%(\mathrm{w} /$ v)] and then with $70 \%$ ethanol for 45 seconds. Finally, the explants were rinsed 4-6 times with double sterilized distilled water under the aseptic conditions to remove the traces of the above mentioned surface sterilizing agents. About 1.5-2.0 cm long shoot tip explants containing apical dome along with 1-2 leaf primordia were carefully excised from the sterilized segments and immediately inoculated on to the full strength MS medium (Murashige and Skoog, 1962) fortified with $100 \mathrm{mg} / \mathrm{L}$ myo-inositol, $30 \mathrm{~g} / \mathrm{L}$ sucrose, $N^{6}$ benzylaminopurine (BAP) and $N^{6}$-furfuryladenine (Kinetin) $[0.5 \mathrm{mg} / \mathrm{L}$ each] and solidified by $0.8 \%(\mathrm{w} / \mathrm{v})$ bacteriological grade agar (Hi-media, India). The $\mathrm{pH}$ of the culture media was adjusted to 5.8 prior to autoclaving at $121^{\circ} \mathrm{C}$ and $1.06 \mathrm{~kg} \mathrm{~cm}^{-2}$ for $20 \mathrm{~min}$. All the cultures were incubated at $25 \pm 2^{\circ} \mathrm{C}$ and $40 \mu \mathrm{mol}^{-2} \mathrm{~s}^{-1}$ for $16 \mathrm{~h} / 8 \mathrm{~h}$ light/dark photoperiod, provided by cool white fluorescent tubes (Philips, India). After six weeks of inoculation, established shoot cultures were transferred onto fresh MS media supplemented with higher concentrations of both $2.0 \mathrm{mg} / \mathrm{L} \mathrm{BAP}+2.0 \mathrm{mg} / \mathrm{L}$ Kinetin [MS-2 Media] for further multiplication. Thereafter, Four weeks old multiplicated shoots $(1.0-2.0 \mathrm{~cm})$ were isolated and individually subcultured onto same MS media to obtain enough mother stock cultures for various experiments. All the above mentioned in vitro practices were carried out in Sugarcane Tissue Culture Laboratory at the same University.

Effect of temperature on shoot multiplication: To know the effects of temperature on shoot multiplication, the established plantlets were subcultured separately at different temperatures (i.e. 15, 20, 25, 30 and $35^{\circ} \mathrm{C}$ ) for growth. The cultures to be grown at 20 and $35^{\circ} \mathrm{C}$ were maintained in illuminated BOD incubator while those at 25 and $30^{\circ} \mathrm{C}$, were placed in the growth rooms. The temperature in each case was adjusted manually by using temperature regulator switches. In this case, the culture media $\mathrm{pH}$ was adjusted to 6.0 and photoperiods regulated at $16 \mathrm{~h} / 8 \mathrm{~h}$ light/dark periods.

Effects of photoperiod on shoot multiplication: To know the effects of photoperiod on shoot multiplication, the established plantlets were kept under 8, 12, 16 hrs photoperiods and one set was exposed to continuous light. Arrangements were made in the growth room using cyclic timer switches to regulate the photoperiod. The culture room temperature was maintained at $25 \pm 2^{\circ} \mathrm{C}$ and culture media $\mathrm{pH}$ adjusted to 6.0.

Effects of culture media pH on shoot multiplication: To investigate the effects of culture media $\mathrm{pH}$ on growth and multiplication of shoot cultures, the established plantlets were subcultured separately on media having $\mathrm{pH}$ values 5.2, 5.4, 5.6, 5.8, 6.0, 6.2 and 6.4. The $\mathrm{pH}$ was adjusted with $0.1 \mathrm{~N} \mathrm{NaOH}$ or $0.1 N \mathrm{HCl}$ before autoclaving. The photoperiod was regulated at $16 \mathrm{~h} / 8 \mathrm{~h}$ light/dark periods and culture room temperature maintained at $25 \pm 2^{\circ} \mathrm{C}$.

Experimental design and data analysis: All the experiments were conducted in a complete randomized design (CRD) with a minimum of twelve replicates $(n=12)$ per treatment and repeated thrice. One replicate means one culture vessel. After the 4-weeks of treatments, data on shoot multiplication was recorded for all cultures. The effect of different treatments on various parameters was quantified and the significance of difference among means was determined by analysis of variance (ANOVA) using SPSS version 16.0 (SPSS, Chicago, USA) followed by Duncan's New Multiple Range Test $(\mathrm{DMRT})$ at $\mathrm{p}<0.05$. Data are presented here in the form of mean \pm standard deviation (SD).

\section{RESULTS AND DISCUSSION}

The present investigation suggested that environmental conditions play a significant role in the stipulation of in vitro shoot multiplication. The various responses observed in both the sugarcane genotypes in terms of temperature, $\mathrm{pH}$ and photoperiod effect are illustrated here in detail.

Effect of temperature on shoot multiplication: Data presented in table-1 clearly demonstrates that the variations in culture room temperature have noticeable effects on culture establishment and shoot multiplication in both the sugarcane genotypes used in the present study. At lower temperature (i.e. $15 \pm 1^{\circ} \mathrm{C}$ ), the establishment of culture was as low as $8.2 \pm 0.73$ in Co89003 and 6.9 \pm 0.46 in Co98014 with $48.6 \pm 1.48$ and $42.8 \pm 1.64$ percent shoot regeneration respectively. An increase in temperature by $5^{\circ} \mathrm{C}$ significantly increased the frequency of culture establishment in both genotypes. Highest shoot multiplication $(94.6 \pm 2.23 \%$ and $91.8 \pm 3.21 \%$ in $\mathrm{Co} 89003$ and Co98014 respectively) with $18.7 \pm 1.62$ and $14.9 \pm 1.68$ shoots/culture was ob- 
Table. 1. Effects of culture room temperature on in vitro shoot multiplication in two sugarcane genotypes after 4-weeks of explant inoculation on MS-2 media [Mean \pm SD].

\begin{tabular}{ccccc}
\hline Temperature $\left({ }^{\circ} \mathbf{C}\right)$ & \multicolumn{2}{c}{$\mathbf{C o 8 9 0 0 3}$} & \multicolumn{2}{c}{ Co98014 } \\
\cline { 2 - 5 } & $\begin{array}{c}\text { Shoot regeneration } \\
\text { \% }\end{array}$ & $\begin{array}{l}\text { Average number of } \\
\text { shoots/culture }\end{array}$ & $\begin{array}{c}\text { Shoot regeneration } \\
\text { \% }\end{array}$ & $\begin{array}{l}\text { Average number of } \\
\text { shoots/culture }\end{array}$ \\
\hline $15 \pm 1$ & $48.6 \pm 1.48^{\mathrm{b}}$ & $8.2 \pm 0.73^{\mathrm{a}}$ & $42.8 \pm 1.64^{\mathrm{c}}$ & $6.9 \pm 0.46^{\mathrm{c}}$ \\
$20 \pm 1$ & $56.7 \pm 1.93^{\mathrm{c}}$ & $12.9 \pm 1.26^{\mathrm{c}}$ & $54.3 \pm 2.37^{\mathrm{a}}$ & $10.3 \pm 0.72^{\mathrm{b}}$ \\
$25 \pm 1$ & $94.6 \pm 2.23^{\mathrm{d}}$ & $18.7 \pm 1.62^{\mathrm{e}}$ & $91.8 \pm 3.21^{\mathrm{d}}$ & $14.9 \pm 1.68^{\mathrm{d}}$ \\
$30 \pm 1$ & $78.5 \pm 2.36^{\mathrm{b}}$ & $14.8 \pm 1.53^{\mathrm{d}}$ & $72.3 \pm 2.82^{\mathrm{b}}$ & $11.7 \pm 1.34^{\mathrm{c}}$ \\
$35 \pm 1$ & $49.4 \pm 1.27^{\mathrm{a}}$ & $6.1 \pm 0.48^{\mathrm{b}}$ & $52.6 \pm 1.33^{\mathrm{a}}$ & $7.4 \pm 0.39^{\mathrm{a}}$ \\
\hline
\end{tabular}

Data represents here, the mean \pm SD of 12 replicates per treatment in three repeated experiments. Each mean values followed by the same letter does not differ significantly according to Duncan's multiple rang test $(\mathrm{p} \leq 0.05)$.

Table. 2. Effects of photoperiod on in vitro shoot multiplication in two sugarcane genotypes after 4-weeks of explant inoculation on MS-2 media [Mean \pm SD].

\begin{tabular}{ccccc}
\hline $\begin{array}{c}\text { Photoperiod } \\
\text { (hrs. at 4000 lux light } \\
\text { intensity) }\end{array}$ & \multicolumn{2}{c}{ Co89003 } & \multicolumn{2}{c}{ Co98014 } \\
\cline { 2 - 5 } & $\begin{array}{c}\text { Shoot regeneration } \\
\text { \% }\end{array}$ & $\begin{array}{c}\text { Average number of } \\
\text { shoots/culture }\end{array}$ & $\begin{array}{c}\text { Shoot regeneration } \\
\text { \% }\end{array}$ & $\begin{array}{c}\text { Average number of } \\
\text { shoots/culture }\end{array}$ \\
\hline 8.0 & $39.6 \pm 1.03^{\mathrm{c}}$ & $6.6 \pm 0.93^{\mathrm{b}}$ & $34.8 \pm 1.57^{\mathrm{d}}$ & $3.9 \pm 0.84^{\mathrm{a}}$ \\
12.0 & $48.7 \pm 2.43^{\mathrm{a}}$ & $11.8 \pm 1.78^{\mathrm{d}}$ & $45.3 \pm 2.12^{\mathrm{b}}$ & $9.7 \pm 1.24^{\mathrm{c}}$ \\
16.0 & $81.4 \pm 3.17^{\mathrm{e}}$ & $16.4 \pm 2.09^{\mathrm{b}}$ & $79.7 \pm 2.38^{\mathrm{c}}$ & $13.9 \pm 2.46^{\mathrm{b}}$ \\
20.0 & $43.8 \pm 2.31^{\mathrm{b}}$ & $8.7 \pm 1.16^{\mathrm{c}}$ & $40.6 \pm 2.25^{\mathrm{a}}$ & $7.9 \pm 0.42^{\mathrm{d}}$ \\
Continuous light & $32.6 \pm 2.67^{\mathrm{d}}$ & $5.6 \pm 1.42^{\mathrm{a}}$ & $36.9 \pm 1.14^{\mathrm{e}}$ & $4.7 \pm 0.64^{\mathrm{b}}$ \\
\hline
\end{tabular}

Data represents here, the mean \pm SD of 12 replicates per treatment in three repeated experiments. Each mean values followed by the same letter does not differ significantly according to Duncan's multiple rang test $(\mathrm{p} \leq 0.05)$.

Table. 3. Effects of culture media $\mathrm{pH}$ on in vitro shoot multiplication in two sugarcane genotypes after 4-weeks of explant inoculation on MS-2 media [Mean \pm SD].

\begin{tabular}{|c|c|c|c|c|}
\hline \multirow[t]{2}{*}{ pH of culture media } & \multicolumn{2}{|c|}{$\mathrm{Co89003}$} & \multicolumn{2}{|c|}{ Co98014 } \\
\hline & $\begin{array}{c}\text { Average number of } \\
\text { shoots/culture }\end{array}$ & Shoot growth" & $\begin{array}{c}\text { Average number of } \\
\text { shoots/culture }\end{array}$ & Shoot growth" \\
\hline 5.2 & $4.3 \pm 0.50^{\mathrm{d}}$ & + & $4.1 \pm 0.35^{\mathrm{e}}$ & + \\
\hline 5.4 & $7.3 \pm 0.80^{\mathrm{a}}$ & + & $6.2 \pm 0.57^{\mathrm{c}}$ & + \\
\hline 5.6 & $9.4 \pm 1.10^{\mathrm{c}}$ & ++ & $8.9 \pm 0.74^{\mathrm{a}}$ & ++ \\
\hline 5.8 & $12.8 \pm 1.90^{\mathrm{b}}$ & +++ & $11.3 \pm 1.82^{\mathrm{d}}$ & +++ \\
\hline 6.0 & $17.6 \pm 2.45^{\mathrm{a}}$ & +++ & $13.4 \pm 2.73^{\mathrm{c}}$ & +++ \\
\hline 6.2 & $14.5 \pm 2.24^{\mathrm{e}}$ & +++ & $10.4 \pm 2.03^{\mathrm{a}}$ & +++ \\
\hline 6.4 & $8.7 \pm 0.74^{\mathrm{c}}$ & ++ & $4.6 \pm 0.47^{b}$ & ++ \\
\hline
\end{tabular}

*Here, + (Poor), ++ (Moderate), +++ (Good) shoot growth

Data represents here, the mean \pm SD of 12 replicates per treatment in three repeated experiments. Each mean values followed by the same letter does not differ significantly according to Duncan's multiple rang test $(\mathrm{p} \leq 0.05)$.

served at $25 \pm 1^{\circ} \mathrm{C}$ (Fig.-1). At $30 \pm 1^{\circ} \mathrm{C}$ and $35 \pm 1^{\circ} \mathrm{C}$, the shoot multiplication rate was significantly reduced in both genotypes. Higher temperature (i.e. $35 \pm 1^{\circ} \mathrm{C}$ ) was found unfavorable for both sugarcane genotypes as markedly low number of explants/culture. The growth room temperature also exerted a marked effect on rate of shoot multiplication. The number of shoots produced at either $20^{\circ} \mathrm{C}$ or $35^{\circ} \mathrm{C}$ was considerably low in both genotypes. Shoots developed at $25-30^{\circ} \mathrm{C}$ were healthy, vigorous and green however at $35^{\circ} \mathrm{C}$ the shoots were smaller in size, bore curved leaves and showed burning symptoms in many cultures. These results indicate that the growth of shoots is directly or indirectly dependent upon culture room temperatures. Our results were in conformity with the reports of some earlier studies (Mishra, 2011; Sengar et al.,
2011; Sharma et al., 2015) and dissimilar with Singh (2005). In their study, Singh (2005) observed best shoot multiplication in sugarcane at higher temperatures $\left(30^{\circ} \mathrm{C}\right)$. These results indicate the genotype dependent nature of sugarcane in vitro. In some species like as Galanthus, potato, Narcissus and Allium, lower temperature (between $15-18^{\circ} \mathrm{C}$ ) was favorable for the proper growth of cultures but some tropical plant species i.e., palm tree and Manastera diliciosa requires higher temperatures between 27$30^{\circ} \mathrm{C}$ for their vigorous growth in vitro (Fonnesbech and Fonnesbech, 1980; Tisserat, 1981).

Effect of photoperiod on shoot multiplication: Various photoperiods (i.e. 8, 12, 16h and continuous light) were used at an intensity of 4000 lux. The results presented in table- 2 indicate that the frequency of culture establishment increased as photoperiod increased up to 


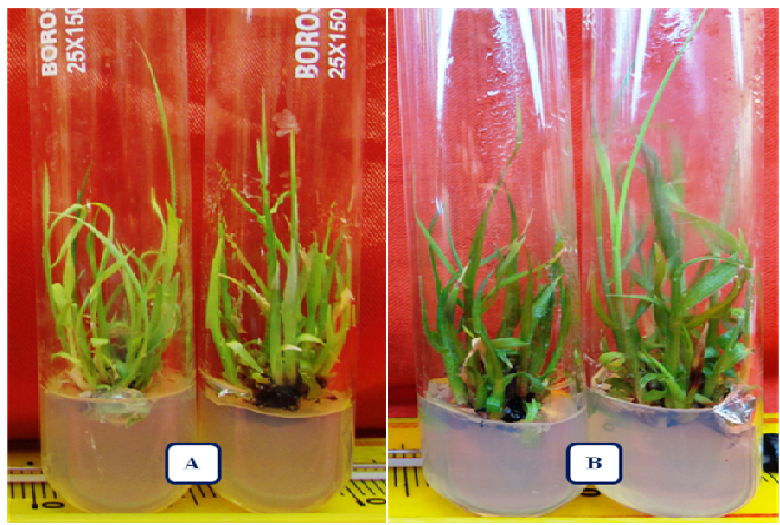

Fig. 1. In vitro shoot multiplication in two sugarcane genotypes after 4 weeks at $25^{\circ} \mathrm{C}, \mathrm{pH} 6.0$ and $16 \mathrm{~h}$ photoperiod, 4000 lux light intensity. Here, (A) Co98014 (B) Co89003. Full strength MS media was supplemented with BAP + Kinetin $(2.0 \mathrm{mg} / \mathrm{L} \mathrm{each})+100 \mathrm{mg} / \mathrm{L}$ myo-inositol $+30 \mathrm{~g} / \mathrm{L} \mathrm{su}$ crose $+8.0 \mathrm{~g} / \mathrm{L}$ of bacteriological grade agar powder.

$16 \mathrm{~h}$ in both the sugarcane genotypes; however, it decreased under continuous light condition. Present study gave best shoot multiplication results at $16 \mathrm{~h}$ photoperiod in both genotypes. In genotype Co89003, the establishment was recorded to be $81.4 \pm 3.17 \%$ with $16.4 \pm 2.09$ shoots/culture at $16 \mathrm{~h}$ photoperiod followed by $48.7 \pm 2.43 \%$ with $11.8 \pm 1.78$ shoots/culture at $12 \mathrm{~h}$ photoperiod whereas, genotype Co98014 showed maximum $79.7 \pm 2.38 \%$ shoot regeneration with $13.9 \pm 2.46$ shoots/culture at $16 \mathrm{~h}$ photoperiod (Fig.-1). The results suggested that the average number of shoot/culture increased as the duration of light increased. Maximum (16.4 \pm 2.09 shoots/culture) was recorded in genotype $\mathrm{Co} 89003$ at $16 \mathrm{~h}$ photoperiod whereas; it was minimum $(3.9 \pm 0.84$ shoots/culture) in genotype Co98014 under $8 \mathrm{~h}$ photoperiod. Shoots regenerated at $16 \mathrm{~h}$ photoperiod were morphologically better as compared to other tested photoperiods in both genotypes. Maximum $(81.4 \pm 3.17 \%)$ explants successfully established under 16h photoperiod in Co89003, whereas the frequency of culture establishment was significantly low $(32.6 \pm 2.67 \%)$ under continuous light. In their studies, several other researchers have reported the effects of photoperiod on growth and morphogenesis in different plant species including plum (Morini et al., 1991), potato (Kozai et al., 1995), Anigozanthos bicolor \& Zieria fraseria (Tapingkae and Tajii, 2000), Alocasia amazonica (Jo et al., 2008) and sugarcane (Ramanand and Lal, 2004; Singh, 2005; Sharma et al., 2015). Our results were in conformity with the reports of some earlier studies on sugarcane (Geetha et al., 2000; Lal, 2003; Wagih et al., 2004; Lal et al., 2008; Mishra, 2011; Sengar, 2011; Sharma et al., 2015). In an earlier study, Jain et al. (1997) found that 16h photoperiod was best for optimum growth of plant cultures and later these results were also followed by few other workers for the establishment of efficient in vitro plant regeneration protocols in sugarcane (Ramanand and Lal M, 2004; Wagih et al., 2004).

Effect of culture media $\mathrm{pH}$ on shoot multiplication: Data presented in Table-3 clearly demonstrates the effects of $\mathrm{pH}$ (5.2-6.4) on in vitro shoot multiplication in two sugarcane genotypes viz. Co89003 and Co98014. According to the results obtained in the present study, it is concluded that the rate of shoot multiplication and shoot growth was highly influenced by the $\mathrm{pH}$ of culture media. Best shoot regeneration responses were obtained at media $\mathrm{pH} 6.0$ in both the genotypes studied followed by media $\mathrm{pH}$ 5.8. In the present study, genotype Co89003 showed highest shoot regeneration with $17.6 \pm 2.45$ shoots/culture whereas, Co98014 showed 13.4 \pm 2.73 shoots/culture at the same $\mathrm{pH}$ (Fig.-1). At lower (5.2) and higher (6.4) $\mathrm{pH}$ both genotypes showed reduced shoot regeneration. Shoot growth was also poor on this $\mathrm{pH}$. At $\mathrm{pH}$ 5.8-6.2, both genotypes showed vigorous and green shoots with a good growth. The results obtained in the current study showed that increasing in $\mathrm{pH}$ significantly increased shoot regeneration in both genotypes whereas the higher $\mathrm{pH}$ reduced shoot growth. Present study suggested that the responses regarding multiplication of shoot cultures were also influenced due to $\mathrm{pH}$ of the culture medium. Our results were similar with the findings of some earlier workers as reported in case of sugarcane (Ramanand and Lal, 2004; Singh, 2005; Mishra, 2011; Sengar et al., 2011; Sharma et al., 2015). In their studies, Ramanand and Lal (2004) and Singh (2005) reported that the shoot multiplication rate in sugarcane was higher at $\mathrm{pH} 6.0$ whereas, $\mathrm{pH} 5.6$ and 5.8 gave poor shoot regeneration responses.

\section{Conclusion}

The aforementioned observations reported in the present study conclude that in vitro shoot regeneration and multiplication in sugarcane genotypes was highly influenced by various culture environmental conditions including media $\mathrm{pH}$, photoperiod and temperature. Both sugarcane genotypes showed highest shoot multiplication at growth room temperature $25^{\circ} \mathrm{C}, 16 \mathrm{~h} / 8 \mathrm{~h}$ light/dark photoperiod and culture media $\mathrm{pH}$ 6.0. In the present study, genotype Co89003 exhibited best shoot regeneration responses under different culture environmental conditions. Therefore, the present study suggests that it is necessary to investigate the effects of above mentioned culture environmental conditions on plant growth and development before establishing efficient in vitro plant regeneration protocols for commercial purposes in this bio-energy crop due to its genotype dependent nature.

\section{ACKNOWLEDGEMENTS}

Authors are grateful to the Vice-chancellor and Director, Experimental Station, SVPUA\&T, Meerut, Uttar 
Pradesh for providing laboratory and field facilities to conduct the present research work.

\section{REFERENCES}

Alam, M. Z., Haider, S. A., Islam, R. and Joarder, O. J. (1995). High frequency in vitro plant regeneration in sugarcane. Sugarcane, 6: 20-21.

Arencibia, A.E., Carmona, P., Tellez, M.T., Chan, S.M., Yu, L., Trujillo, and Oramas, P. (1998). An efficient protocol for sugarcane (Saccharum spp.) transformation mediated by Agrobacterium tumefaciens. Transgenic Research, 7: 213-222.

Commodity Research Bureau. (2015). The 2015 CRB commodity yearbook. Chicago, IL: Commodity Research Bureau.

FAO (2013). www.fao.org

FAOSTAT. (2015). Statistical Division: Production domainCrops. Updated on November 24, 2015; Retrieved on December 18, 2015

Fonnesbech, A. and Fonnesbech, M. (1980). In Vitro propagation of Monstera deliciosa. Horticultural Science, 15: 740-741.

Geetha, S., Padmanabhan, W., Manuel, W.W. and Ayyamperumal, A. (2000). In Vitro production of sugarcane plants. Sugar Tech, 2(3): 47-48.

Hendre, R.R., Mascarenhas, A.F., Nadgir, A.L., Pathak M. and Jagannathan, V. (1975). Growth of sugarcane mosaic virus-free sugarcane plants from apical meristems. Indian Phytopathology, 28: 175-178.

Jain, A., Inderjeet., Dhawan, A.K. and Dendsay, J.P.S. (1997). An efficient protocol for micropropagation in sugarcane. In: Proc. Natl. Sem. on Sucrose Synthesis and Recovery in Sugarcane: Issuses and Dimensions. Oct. 8-9, (1997), Karnal (Haryana). pp. 179-182.

Jalaja, N.C., Neelamathi, D. and Sreenivasan, T.V. (2008). Micropropagation for quality seed production in sugarcane. In: Manual on micropropagation for quality seed production in sugarcane in Asia and the Pacific. Food and Agriculture Organization of the United Nations (FAO), Rome. pp. 1-30.

Jo, E.A., Tiwari, R.K., Hahn, E.J. and Paek K.Y. (2008). Effect of photoperiod and light intensity on in vitro propogation of Alocasia amazonica. Plant Biotechnology Reports, 2: 207-212.

Kozai, T., Watanabe, K. and Jeong, B.R. (1995). Stem elon- gation and growth of potato (Solanum tuberosum L.) in vitro in response to photosynthetic photon flux, photoperiod and difference in photoperiod and dark period temperature. Scientia Horticulturae, 64: 1-9.

Lal, M., Singh, R.K., Srivastava, S., Singh, N., Singh, S.P. and Sharma, M.L. (2008). RAPD worker used analysis of micropropagated plantlets of Sugarcane for early evaluation of genetic fidelity. Sugar Tech, 10: 99-103.

Lal, N. (2003). High frequency of plant regeneration from sugarcane callus. Sugar Tech, 5(1\&2): 89-91.

Mishra, S. (2011). Effect of Temperature, Photoperiod and $\mathrm{pH}$ on in vitro shoot multiplication of sugarcane. Vegetos, 24(1): 50-53.

Morini, S., Sciutti, R., Muleo, R. and Fortuma, P. (1991). Growth patterns of "in vitro" cultured shoot tips as influenced by different light - dark regimes. Acta Horticulturae, 289: 137-138.

Murashige, T. and Skoog, F. (1962). A revised medium for rapid growth and bio assays for tobacco tissue cultures. Physiologia Plantarum, 15: 473-497.

Ramanand and Lal, M. (2004). An efficient protocol for in vitro micropropagation of sugarcane. Sugar Tech, 6 (1\&2): 85-87.

Sengar, K., Sengar, R.S. and Garg, S.K. (2011). The effect of in vitro environmental conditions on some sugarcane varieties for micropropagation. African Journal of Biotechnology, 10(75): 17122-17126.

Sharma, M.K., Sengar, R.S., Chand, P., Singh, R., Kumar, P., Gupta, S. and Yadav, M.K. (2015). Effects of temperature, photoperiod and $\mathrm{pH}$ of culture media on in vitro shoot multiplication in sugarcane genotypes. Progressive Agriculture, 15(1): 104-108.

Singh, A. (2005). Physiological and biochemical basis of in vitro morphogenesis in sugarcane hybrids. Thesis submitted to CSM University, Kanpur, UP, India.

Tapingkae, T. and Tajii, A. (2000). Light quality and quantity: their effects on in vitro growth and development of two Australian plant species. Acta Horticulturae, 541: 281-288.

Tisserat, B. (1981). Date Palm tissue culture, U.S. Department of Agriculture Research Service, Oakland, California.

Wagih, M.E., Ala, A. and Musa, Y. (2004). Regeneration and evaluation of sugarcane somaclonal variants for drought tolerance. Sugar Tech, 6(1\&2): 35-40. 